\title{
Ontologies for Semantically Interoperable Electronic Commerce
}

\author{
Leo Obrst ${ }^{1}$, Howard $\mathrm{Liu}^{2}$, Robert Wray ${ }^{3}$, and Lori Wilson ${ }^{2}$ \\ 'MITRE, USA, ${ }^{2}$ self employed ${ }^{2}$ Soar Technology, USA, lobrst@mitre.org
}

\begin{abstract}
In this paper we discuss the use of ontologies to support semantically interoperable B2B electronic commerce. First, we describe the nature of B2B and the kinds of applications used. Second, we present arguments towards why B2B needs ontologies and the nature of the problems faced. Finally, we discuss the interaction of ontologists and domain experts in the building of ontologies for business, and some of the tools available for developing ontologies.
\end{abstract}

\section{INTRODUCTION}

We are interested in ontologies in the product and service space to support semantically interoperable Business-to-Business (B2B) electronic commerce (e-commerce). Ontologies in this space include domain ontologies (lower ontologies), an upper ontology and upper model, and shared middle ontologies, as in Fig. 1. We are assisted by subject matter (domain) experts who know various technical product areas. Although difficult problems remain to be solved (Obrst, et al, 2001), we firmly believe that ontologies remain the best solution for robust, semantically interoperable electronic commerce, as they do for many other applications.

An ontology defines the common words and concepts (meanings) used to describe and represent an area of knowledge. Ontologies are used by people, databases, and applications that need to share domain information (a domain is just a specific subject area or area of knowledge, like medicine, automobile repair, banking, tool manufacturing, etc.) Ontologies include computerusable definitions of basic concepts in the domain and the relationships 
among them. They encode knowledge in a domain and also knowledge that spans domains. They represent shared conceptualizations.

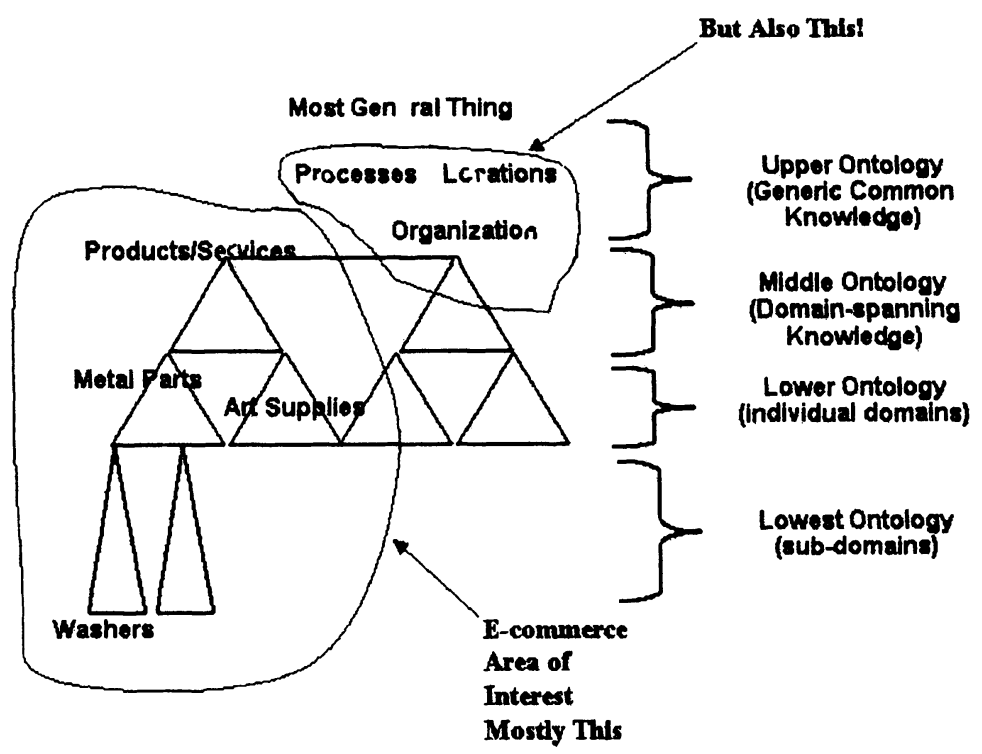

Figure 1: Upper, Middle, and Lower Ontology

\section{THE NATURE OF THE BUSINESS-TO-BUSINESS (B2B) ENTERPRISE}

B2B electronic commerce is everything that land commerce is, plus more: automated support for information and transaction flow for vertical and horizontal commercial interoperability. Given this definition, B2B provides marketplace platforms on the Internet that support the following:

- Multiple trading models. Trading models include auctions, reverse auctions, exchanges, Request-For-Proposal/Request-For-Quote, bookstores, trading hubs, etc. The platforms are used for and by commercial organizations.

- Rich information content on products and services for both buyers and sellers. This content might be realized in the form of catalogs, product guides, market and domain editorial content, news, advertising. The information content may also be annotated in machine understandable form, as well as organized and tailored for human use. 
- Support for buying and selling. B2B transactions often require much more than the simple exchange of goods for money. Support functions include financing, privacy/security, payment processing, order management, profiling/personalization, product configuration, planning/scheduling and forecasting, product life cycle and inventory management, business processes, workflow, and rules, logistics, distribution, and delivery.

\section{WHY ONTOLOGIES ARE NEEDED FOR B2B}

B2B e-commerce needs ontologies to support semantic interoperability. Consider two critical motivations for ontologies in B2B e-commerce. First, there is an informational use. An ontology is a structured conceptual model of an e-commerce domain. This structuring of the information space supports parametric search and navigation using product and service knowledge by prospective buyers to discover what to buy, and subsequently to determine pricing and availability. In this case, fairly static knowledge embodied in the ontology (e.g., this retailer sells ball peen hammers) maps to the dynamic data of the vendors (model numbers of the hammers of manufacturers, distributors carrying specific models, selling prices, etc.). Furthermore, an ontology can model not only product and service knowledge, but also knowledge about buyers and sellers, i.e., users. By employing user role

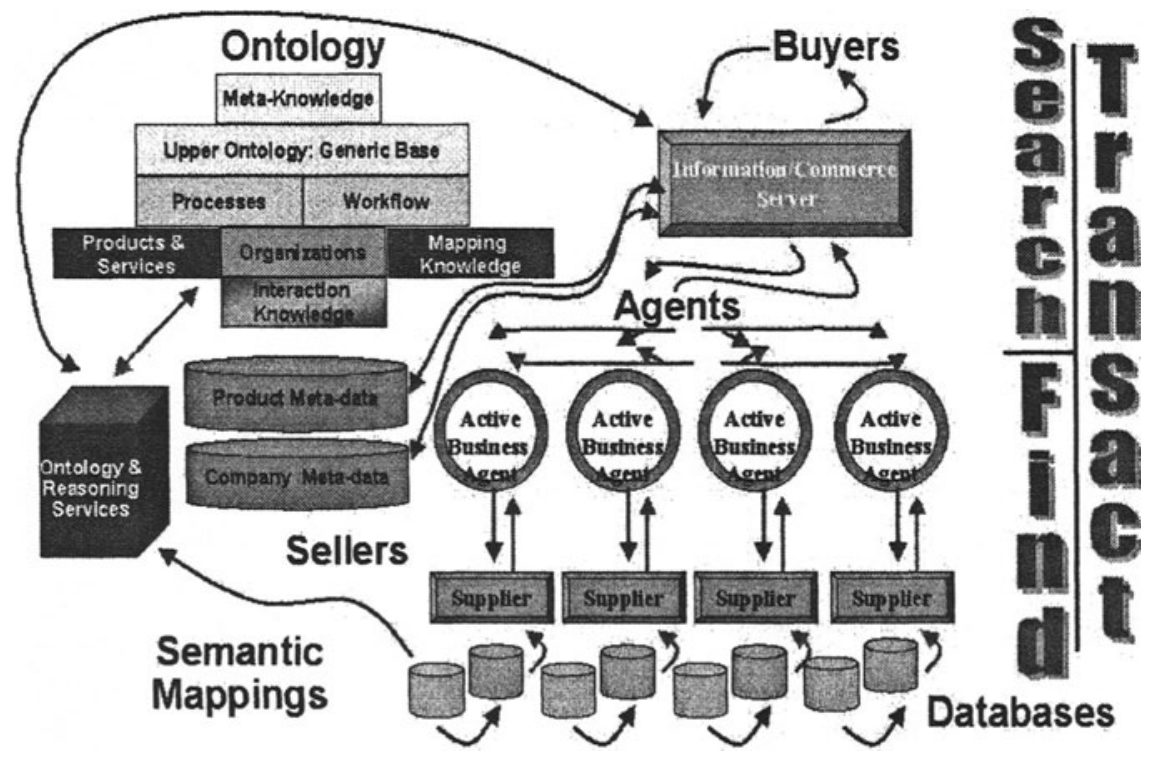

Figure 2: An E-Commerce Application Using Ontologies 
knowledge (sometimes called user profiling or personalization), for example, queries can be customized relative to that user's experience and interests.

E-commerce also needs ontologies for transactional purposes. Knowledge of a company's organizational structure, workflow, processes, and products/services can be used to assist directly in buying and selling. For example, Fig. 2 depicts one view of an architecture and flow of knowledge within a prospective ontology-driven B2B marketplace infrastructure, linking buyers to semantically mapped suppliers via software agents or webbased service-oriented applications for both informational and transactional purposes. In this framework, multiple heterogeneous databases map to a common ontology that thus enables a meaningful comparative view to be displayed to a prospective buyer.

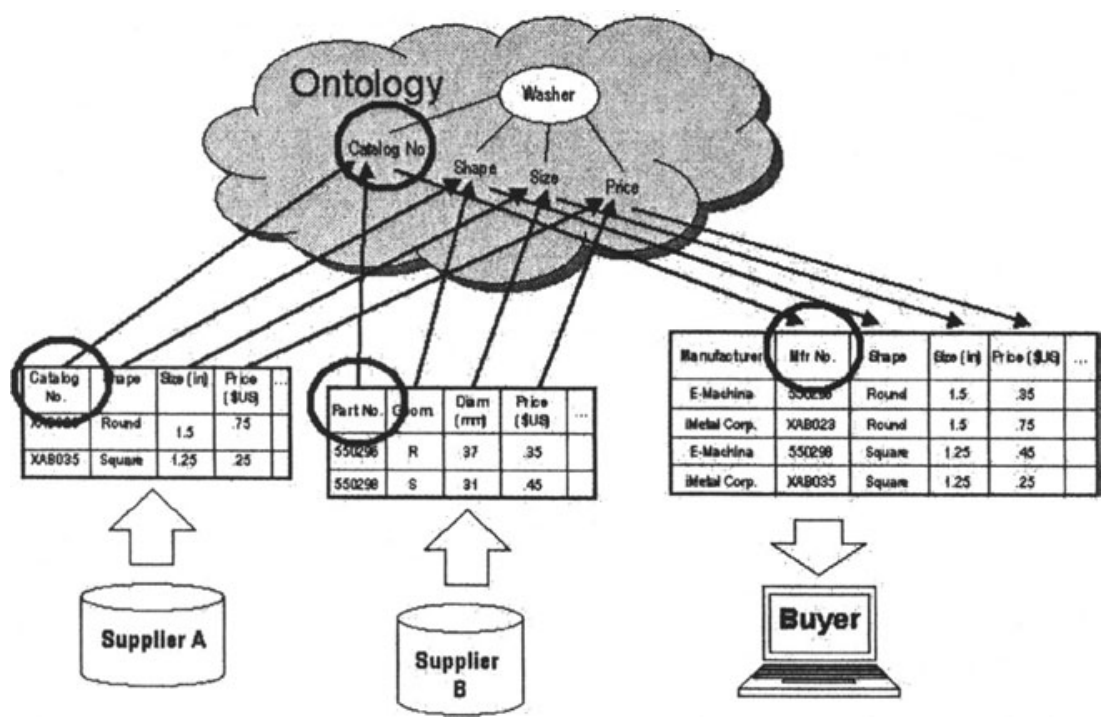

Figure 3: Buyers and Sellers Linked by Ontology

The use of ontologies in e-commerce thus goes a long way towards solving two unsolved obstacles to successful B2B E-Commerce that involve semantic interoperability. The heterogeneous vendor database problem results from distributors, manufacturers, service providers with databases that differ significantly in format, structure, and meaning. In Fig. 3, different suppliers use different fields for conceptually similar products. The buyer should not have to refer to "Part Number" to look at one vendors product, and "Catalog Number" in another. As the figure shows, the ontology provides a consistent 
representation for the heterogeneous databases, with mappings from the ontology representation to the specific databases.

The second problem ontologies address is the standards and common vertical conceptual model problem. What is the meaning of the terminology employed in the product and service space and the relationships between terms? In Fig. 3, what is a washer? Obvious choices include a part used with nuts and bolts and a colloquialism for a household appliance. Which is meant? Ontologies can provide formalizations of the concepts underpinning common business terminology, and this formalized meaning can be made sound, consistent, extensible, reusable, modular, and logical.

Ontologies must be built to support the representation requirements of many IT applications, most of which will presume some form of classification of products and services. However, many business classification systems are ad hoc, inconsistent, and non-integrated, with little association between classification systems. In order to address this apparent incompatibility, we suggest a distinction be made between representation and presentation. Representation is the underlying structure and codification of the product and service knowledge space to be supplied by the eventually developed ontologies. This representation is semantically sound, consistent (though incomplete in the sense that additional refinement could always be made), controlled, modular, reusable, and provides some support for application presentation needs.

Presentation remains largely the responsibility of the application. Applications could choose to use their own terminology and classification display, as long as that terminology and structure had linkages to the underlying representation. An application intended for a buyer, for example, might display a different structure and terminology from that of an application intended for a seller. Furthermore, even within a buyer application, the terminology and displayed structure could be different based on the role of the prospective buyer/user. For example, a technically savvy engineer using a catalog search application would typically employ search terminology (or equivalently, navigation through a classification system/taxonomy) based on technical specifications. Within the ontology, this terminology would be entity-centric and use entity-centric concepts. An entity in this usage is typically a thing, i.e., a product object. But a non-technical purchasing analyst would typically employ search terminology based on his/her own company's environment or processes. Within the ontology, the terminology would thus use process- or function-centric representation). In either case, however, the navigational path employed (via relational links or inference) should arrive at the identical, parameterized product or service. Ontologies would thus at least partially support multiple ways of presenting the product and service information. 
The vision, of course, for using a common representation is to enable a consistent ontological or conceptual search across data and applications, so that semantically meaningful documents and data concerning products and services are returned to the user. This search by definition includes the notion of parametric search, which is related to the notion of product configuration, that is, a search informed by ontological and other properties of the searched-for product/service. Correspondingly, a common representation supports ontological classification of products and services: search assisting primarily buyers, product classification assisting primarily sellers.

Many emerging Web-based standards and languages implicitly define ontologies (example: Unified Business Language (UBL, http://)), and draw upon the experience and expertise of B2B companies (Ariba, CommerceOne, VerticalNet) and electronic commerce consortia (RosettaNet, X12 Electronic Data Interchange, etc.)

\section{ONTOLOGISTS AND DOMAIN EXPERTS}

Domain experts provide knowledge for the ontologies. Ontologists determine how to represent that knowledge. Ontologists usually teach domain experts some of the fundamental concepts about ontologies and ontological engineering, along with how to use ontology editing tools. As soon as domain experts begin creating domain ontologies unassisted, ontologists can shift their responsibilities to formulating designs for an overall knowledge architecture, to set guidelines for building ontologies, to integrate the ontologies with applications, and to enhance the ontology building environment to make the ontologies more expressive and more maintainable.

\section{ONTOLOGY TOOLS}

Ontology development tools are now entering the market. Most of the tools until recently were research tools originally funded by programs of the US Defense Advanced Research Projects Agency (DARPA) (Patil, et al, 1992; Cohen, et al, 1998) such as Ontolingua/Chimaera (McGuinness, et al, 2000) and Protégé (Noy, et al, 2000). Both of these tools use frame-based knowledge representation languages developed for artificial intelligence (AI), such as the Open Knowledge Base Connectivity (OKBC) language (Chaudry, et al, 1998). In contrast, Cyc (Guha \& Lenat, 1990), which has been a commercial product for a number of years uses a first order logic (FOL) based language. One advantage of Cyc is that it provides a freely available upper ontology. An upper ontology (or more appropriately, a set of 
integrated ontologies) attempts to characterize basic, commonsense knowledge notions that humans know so well that we typically don't know we know them: that is, distinctions between kinds of objects in the world (a tangible product vs. an intangible process), events and processes, how parts constitute a whole and what that means, and general notions of time and space.

Other newer tools for creating ontologies include the commercially available:

OntoEdit, (http://) and the research tool OilEd, (http://).

Both of these tools use knowledge representation languages such as:

RDF, (http://) and DAML+OIL, (http://) (itself a fusion of DAML, (http://) and OIL, (http://).

RDF, DAML+OIL, and the newly emerging Ontology Web Language (OWL) are being developed as standards under the W3C, (http://) to support the so-called Semantic Web, (http://), (Berners-Lee, et al, 2001).

Other, more generic tools, which can help build an infrastructure for ontologies, include both Java and Common Lisp (e.g., Allegro Common Lisp, (http://)).

\section{CONCLUSIONS}

Electronic commerce, in general, and B2B e-commerce, in particular, needs ontologies, to ensure semantic interoperability. Ultimately, ontologies provide a lingua franca or trading language, to transact the business of buying and selling. Mature ontologies will serve as an intermediate commercial vocabulary with a common set of meanings or concepts for commercial products and services to which individual, disparate product catalogs, commercial databases, and marketplace applications can map. Given $\mathbf{M}$ buyers and $\mathrm{N}$ sellers, without the use of an intermediate ontology, the problem of integrating between commercial systems and databases is very complex: $\mathbf{M ~ x}$ $\mathrm{N}$ integrations (each buyer to each seller) have to be performed. With the use of ontologies, only $\mathrm{M}+\mathrm{N}$ integrations have to be performed (each buyer or seller to the ontology). That is a huge savings in time, effort, and money for any business. The bottom line is: ontologies save you money, and that's always a competitive advantage. 


\section{REFERENCES}

Allegro Common Lisp, http://franz.com/

Berners-Lee, T. Hendler, J. Lassila, O. (2001), The Semantic Web. In The Scientific American, May, 2001. http://www.scientificamerican.com/2001/0501 issue/050l berners-lee.html

Chaudri, V. Farquhar, A. Fikes, R. Karp, P. D. Rice, J. P. (1998), Open knowledge base connectivity specification. Specification V. 2.0.31, SRI and Knowledge Systems Laboratory, Stanford University.

Cohen, P. Schrag, R. Jones, E. Pease, A. Lin, A. Starr, B. Easter, D. Gunning D. Burke, M. (1998), The DARPA High Performance Knowledge Bases Project. In Artificial Intelligence Magazine. 19 (4), pp.25-49.

DAML, http://www.daml.org/]

DAML+OIL, http://www.daml.org/2001/03/daml+oil-walkthru.html

Guha, R.V. Lenat. D. (1990), Cyc: A mid-term report. Microelectronics Technology and Computer Corporation (MCC), Austin, TX, Technical Report ACT-CYC-134-90.

McGuinness, D. L. Fikes, R. Rice, J. Wilder, S. (2000), An Environment for Merging and Testing Large Ontologies. Proceedings of the Seventh International Conference on Principles of Knowledge Representation and Reasoning (KR2000), Breckenridge, Colorado, USA, April 12-15. Cohn, A.G. Giunchiglia, F. Selman, B. (Eds.), San Francisco, CA: Morgan Kaufman.

Noy, N. F. Fergerson, R. W. Musen, M. A. (2000), The knowledge model of Protege-2000: Combining interoperability and flexibility. In 2nd Intl. Conf. on Knowledge Engineering and Knowledge Management (EKAW'2000).

Obrst, L. Wray, R. Liu, H. (2001), Ontological Engineering for E-Commerce: a Real B2B Example, in Proc. of the International Conference on Formal Ontology in Information Systems (FOIS-2001), Oct. 17-10. http://www.fois.org/fois-2001/index.html

OIL, http://www.ontoknowledge.org/oil/.

OilEd, http://img.cs.man.ac.uk/oil/

OntoEdit, http://ontoserver.aifb.uni-karlsruhe.de/ontoedit/

Patil, R. Fikes, R. Patel-Schneider, D. Mckay, D. Finin, T. Gruber, T. Neches, R. (1992), The DARPA Knowledge Sharing Effort: Progress Report. In Proc. of Knowledge Representation and Reasoning Conference (KR-92).

RDF, http://www.w3.org/RDF/

Semantic Web, http://www.w3.org/2001/sw/

UBL, http://www.oasis-open.org/committees/ubl/

W3C, http://www.w3.org/] 


\begin{tabular}{|c|c|}
\hline Term & Definition \\
\hline DAML+OIL & $\begin{array}{l}\text { DARPA (Defense Advanced Research Projects Agency) Agent } \\
\text { Markup Language-Ontology Inference Layer: these are two XML- } \\
\text { and Web-based languages to support the Semantic Web, which have } \\
\text { recently fused. DAML originated from a US DARPA-sponsored pro- } \\
\text { gram; OIL originated from a European Union-sponsored program. } \\
\text { Together they constitute the most semantically expressive language } \\
\text { available for WWW documents. The combined language is now sup- } \\
\text { ported by the W3C web standards consortium, and is soon to be su- } \\
\text { perseded by the Ontology Web Language (OWL). }\end{array}$ \\
\hline $\begin{array}{l}\text { Frame-based } \\
\text { Knowledge Rep- } \\
\text { resentation Lan- } \\
\text { guage }\end{array}$ & $\begin{array}{l}\text { A knowledge representation language or language for expressing } \\
\text { ontological information derived originally from the artificial intelli- } \\
\text { gence (AI) language called KL-ONE, which itself is one of the earli- } \\
\text { est formalizations of the notion of semantic network. The notion of a } \\
\text { frame comes from the early LISP programming language terminology } \\
\text { used by early KR languages. In frame terminology, a concept is a } \\
\text { class, and a relation is a slot. Attributes (sometimes called properties) } \\
\text { are just slots defined on a domain (a specific class subtree) or one of } \\
\text { its subdomains (a subclass of a domain class). }\end{array}$ \\
\hline OKBC & $\begin{array}{l}\text { Open Knowledge Base Connectivity language. This is a language for } \\
\text { knowledge access and interchange (an API) derived from the Generic } \\
\text { Frame Protocol, developed in the early 1990s by knowledge represen- } \\
\text { tation technologists under the support of the DARPA Knowledge } \\
\text { Sharing Effort (CITATION). This protocol became the OKBC under } \\
\text { the support of the DARPA High Performance Knowledge Base } \\
\text { (HPKB) program, 1996-1999 0. }\end{array}$ \\
\hline Ontology & $\begin{array}{l}\text { An ontology models the meaning of domains of interest: the objects } \\
\text { (things) in domains, the relationships among those things, the proper- } \\
\text { ties, functions and processes involving those things, and constraints } \\
\text { on and rules about those things. }\end{array}$ \\
\hline $\mathrm{RDF} / \mathrm{S}$ & $\begin{array}{l}\text { Resource Definition Framework/Schema. These are two languages. } \\
\text { The first (RDF) expresses instance-level semantic relations phrased in } \\
\text { terms of a triple: <subject, verb, object>, i.e., <objectl, relation } 1 \text {, } \\
\text { object } 2>\text {. The second (RDFS) expresses class level relations describ- } \\
\text { ing acceptable instance level relations. }\end{array}$ \\
\hline Semantic Web & $\begin{array}{l}\text { "The Semantic Web is an extension of the current web in which in- } \\
\text { formation is given well-defined meaning, better enabling computers } \\
\text { and people to work in cooperation." (Berners-Lee, et al, 2001) }\end{array}$ \\
\hline
\end{tabular}

\section{ACKNOWLEDGMENTS}

The views expressed in this paper are those of the authors alone and do not reflect the official policy or position of The MITRE Corporation or any other company or individual. Finally, we wish to thank the anonymous reviewers for their cogent comments and suggestions. 